University of Nebraska - Lincoln

DigitalCommons@University of Nebraska - Lincoln

US Army Research

U.S. Department of Defense

2011

Fatigue-induced grain coarsening in nanocrystalline platinum films

Roi A. Meirom

Pennsylvania State University

Daan Hein Alsem

Hummingbird Scientific

Amber L. Romasco

Pennsylvania State University

Trevor Clark

Pennsylvania State University

Ronald G. Polcawich

US Army Research Laboratory

See next page for additional authors

Follow this and additional works at: https://digitalcommons.unl.edu/usarmyresearch

Part of the Operations Research, Systems Engineering and Industrial Engineering Commons

Meirom, Roi A.; Alsem, Daan Hein; Romasco, Amber L.; Clark, Trevor; Polcawich, Ronald G.; Pulskamp, Jeffrey S.; Dubey, Madan; Ritchie, Robert O.; and Muhlstein, Christopher L., "Fatigue-induced grain coarsening in nanocrystalline platinum films" (2011). US Army Research. 139.

https://digitalcommons.unl.edu/usarmyresearch/139

This Article is brought to you for free and open access by the U.S. Department of Defense at DigitalCommons@University of Nebraska - Lincoln. It has been accepted for inclusion in US Army Research by an authorized administrator of DigitalCommons@University of Nebraska - Lincoln. 


\section{Authors}

Roi A. Meirom, Daan Hein Alsem, Amber L. Romasco, Trevor Clark, Ronald G. Polcawich, Jeffrey S.

Pulskamp, Madan Dubey, Robert O. Ritchie, and Christopher L. Muhlstein 


\title{
Fatigue-induced grain coarsening in nanocrystalline platinum films
}

\author{
Roi A. Meirom ${ }^{\text {a }}$, Daan Hein Alsem ${ }^{\text {b,c,1 }}$, Amber L. Romasco ${ }^{\text {a }}$, Trevor Clark ${ }^{\mathrm{a}}$, \\ Ronald G. Polcawich ${ }^{\mathrm{d}}$, Jeffrey S. Pulskamp ${ }^{\mathrm{d}}$, Madan Dubey ${ }^{\mathrm{b}}$, Robert O. Ritchie ${ }^{\mathrm{b}}$, \\ Christopher L. Muhlstein ${ }^{\mathrm{a}, *}$ \\ ${ }^{a}$ Department of Materials Science and Engineering and The Materials Research Institute, The Pennsylvania State University, \\ 202 B Steidle Building, University Park, PA 16802, USA \\ ${ }^{\mathrm{b}}$ Materials Sciences Division, Lawrence Berkeley National Laboratory, Berkeley, CA, USA \\ ${ }^{\mathrm{c}}$ National Center for Electron Microscopy, Lawrence Berkeley National Laboratory, Berkeley, CA, USA \\ ${ }^{\mathrm{d}}$ US Army Research Laboratory, Adelphi, MD, USA
}

Received 26 August 2010; received in revised form 15 October 2010; accepted 20 October 2010

Available online 18 November 2010

\begin{abstract}
Mechanisms to explain the unique mechanical behavior of nanograined metals focus primarily on grain and grain boundary mobility. In most nanograined metal materials systems (both pure and alloyed) it has not been possible to decouple these time- and cycle-dependent contributions. In contrast, the $460 \mathrm{~nm}$ thick, $\left(\begin{array}{lll}1 & 1 & 1\end{array}\right)$ textured, nanograined platinum thin films evaluated in this work have robust grain morphologies that allow us to uniquely identify the fatigue damage accumulation processes. Unlike other reports of face-centered cubic metal behavior, the platinum films exhibited a particularly limited range of fatigue crack growth $(<3 \mathrm{MPa} \sqrt{ } \mathrm{m})$ with extremely large $(\sim 10.5)$ power law exponents typically associated with fatigue of structural ceramics and ordered intermetallics. Transmission electron microscopy and fatigue crack growth data suggest that the crack growth mechanism appears to be intrinsic in origin and dislocation mediated.
\end{abstract}

(C) 2010 Acta Materialia Inc. Published by Elsevier Ltd. All rights reserved.

Keywords: Fatigue; Thin films; Platinum group

\section{Introduction}

A central challenge to understanding how fatigue damage accumulates in nanograined films has been the limited stability of the structure of the films. In many metallic films (e.g. $\mathrm{Ni}, \mathrm{Cu}$ and $\mathrm{Ag}$ ) the grains spontaneously coarsen ("self-annealing"), a phenomenon that can also be driven by stress [1-6]. Nanocrystalline $\mathrm{Ni}$, for example, has been shown to display a typical power law exponent (between 2 and 3.5) [2,7] and grain coarsening during cyclic contact [8]. It also creeps at room temperature [9], so it is difficult to deconvolute the time- and cycle-dependent mechanisms.

\footnotetext{
* Corresponding author. Tel.: +1 814865 1523; fax: +1 8148652917. E-mail address: clm28@psu.edu (C.L. Muhlstein).

${ }^{1}$ Present address: Hummingbird Scientific, Lacey, WA, USA.
}

Unlike many nanograined metals, the nanoscale, columnar grain morphology of the Pt films studied in this work are remarkably robust. The grain morphology does not spontaneously change at room temperature or during monotonically increasing tensile or indentation loads, and time dependency is restricted to a slight anelastic response [10]. As a result, $\mathrm{Pt}$ is an ideal system for understanding how cycle-dependent deformation and degradation occur in pure, textured, face-centered cubic (fcc) films. In the case of the columnar, stable, nanoscale grain morphologies evaluated in this work, fatigue degradation at low crack growth rates is intimately linked to cyclic grain-coarsening processes, where plasticity appears to be dislocation mediated in spite of the fine grain morphology.

Mechanisms governing plasticity in coarse-grained and macroscale samples are known to break down when the 
microstructural features approach the nanoscale. Understanding the mechanisms governing the mechanical response of nanocrystalline materials would undoubtedly lead to an enhancement of physical properties, but would also provide insight into size and length scale effects in nanoscale specimens and grain morphologies. One of the primary difficulties in establishing these mechanisms is decoupling experimental observation and modeling predictions from the inherent instability of nanograined metals at room temperature, especially in the presence of mechanical stress. This is particularly important because any grain coarsening that occurs in these materials has the potential to undo the benefits of their initially fine grain size.

Investigations into the fatigue response of nanocrystalline materials are very limited, so there are some important gaps in our understanding of how cyclic, tensile and indentation loading modes differ. Despite this, there are a few experimental investigations citing grain coarsening in ultrafine-grained or nanograined materials in response to fatigue loading. The earliest experiment to report grain coarsening in response to fatigue is by Witney et al. [1], who reported on the microstructural evolution of nanocrystalline copper. Since then, other experimental works involving fatigue on nanocrystalline nickel and nickel-tungsten alloys [2], ultrafine-grained copper [3,4] and nickel-manganese alloys [5] have noted grain coarsening. The coarsening has been cited as the reason for the observed cyclic softening in nanocrystalline materials [3] and for contributing to crack initiation [5], but the mechanisms for the growth are still unclear. One investigation, by Zhang et al. [6], reports grain coarsening both at room temperature and at cryogenic temperatures, suggesting that the growth may be dominated by mechanical factors. Several modeling investigations have suggested possible stress-assisted grain-coarsening mechanisms [11-15], but their mechanisms are varied and difficult to decouple from the room-temperature coarsening response found in many experimental investigations.

In general, there is a fundamental lack of understanding of the relationships between stress, plastic deformation, damage accumulation and microstructural evolution in nanocrystalline metals. The path to identifying and characterizing the roles that these factors play in mechanical behavior is to identify and characterize a stable, nanograined material under a variety of loading conditions. The textured, nanocrystalline platinum films in this work have the requisite stability, and were used to identify the deformation behavior of the films under tensile, indentation and fatigue-loading conditions.

\section{Film deposition, structure, chemistry and mechanical testing parameters}

The fatigue crack growth behavior of nanograined metals was evaluated using free-standing, $450 \mathrm{~nm}$ thick, Pt films on top of a $10 \mathrm{~nm} \mathrm{Ti}$ adhesion layer from two fabrication runs. The samples were fabricated at the Army Research Laboratory in Adelphi, MD, and began with a
$100 \mathrm{~mm}$ diameter single crystal silicon wafer $\left(\begin{array}{lll}1 & 0 & 0\end{array}\right)$ substrate. A thin titanium layer followed by a $450 \mathrm{~nm}$ platinum layer were sputter deposited at $50^{\circ} \mathrm{C}$ in order to provide adhesion of the $\mathrm{Pt}$ to the Si substrate. The blanket films underwent a micromachining process (i.e. resist patterning, development, etching and removal) to pattern the specimens into the desired shapes. At the end of this process, $\mathrm{XeF}_{2}$ was used to release the mechanical testing specimens by removing the silicon from underneath them. The resulting free-standing specimens were connected to the substrate at one end and temporarily held at the opposite end by four tethers that were broken manually prior to testing. Areas of the unpatterned Pt film on the Si substrate adjacent to the specimens were used for nanoindentation characterization.

\subsection{Film chemistry and grain morphology}

Samples exhibited clean and optically smooth surfaces that were devoid of flaws such as cracks and plastic deformation such as dents or wrinkles. The structure and chemistry of cross-sections of the $\mathrm{Pt}$ films were evaluated using two $200 \mathrm{kV}$ JEOL transmission electron microscopes. Electron transparent cross-sections of the film were produced by using conventional mechanical and ion milling techniques [16], and were cleaned using oxygen plasma prior to evaluation to minimize carbon contamination of exposed surfaces. Transmission electron microscopy (TEM) established that the platinum films were $460 \mathrm{~nm}$ thick, with columnar grains approximately $25 \pm 10 \mathrm{~nm}$ in diameter and a strong $\left\langle\begin{array}{llll}1 & 1 & 1\end{array}\right\rangle$ texture (Fig. 1). Selected area diffraction patterns reveal a lattice parameter consistent with bulk Pt [17]. Further investigation using energy-dispersive spectroscopy, electron energy loss spectroscopy and secondary ion mass spectroscopy confirmed that the platinum films were free from contamination both within the grains and at grain boundaries to the detectability limits of the instruments $(\sim 0.1$ at.\%) $[16,18,19]$.

\subsection{Specimen characterization}

The tensile and fatigue properties of the platinum films were evaluated using a closed-loop, micromechanical testing system that was composed of three main parts: a piezoelectric translation stage (PI P620), a force transducer (either Transducer Techniques GSO-10 or Sensotec Model 31) and a high-resolution digital camera (Pulnix TM-9701). The camera was paired with long working distance Mitutoyo infinity-corrected lenses, making the final resolution of the optical setup approximately $0.5 \mu \mathrm{m}$. The entire system was situated on a bench top vibration isolation system (Minus K BM-4). Data acquisition and instrument control were performed using an SCXI-based system operating in a LabView 7.0.

Specimens of two types were used: (i) $50 \mu \mathrm{m}$ gauge width, $1.5 \mathrm{~mm}$ gauge length specimens were used for tensile testing and (ii) $2 \mathrm{~mm}$ gauge length center-cracked sheet 

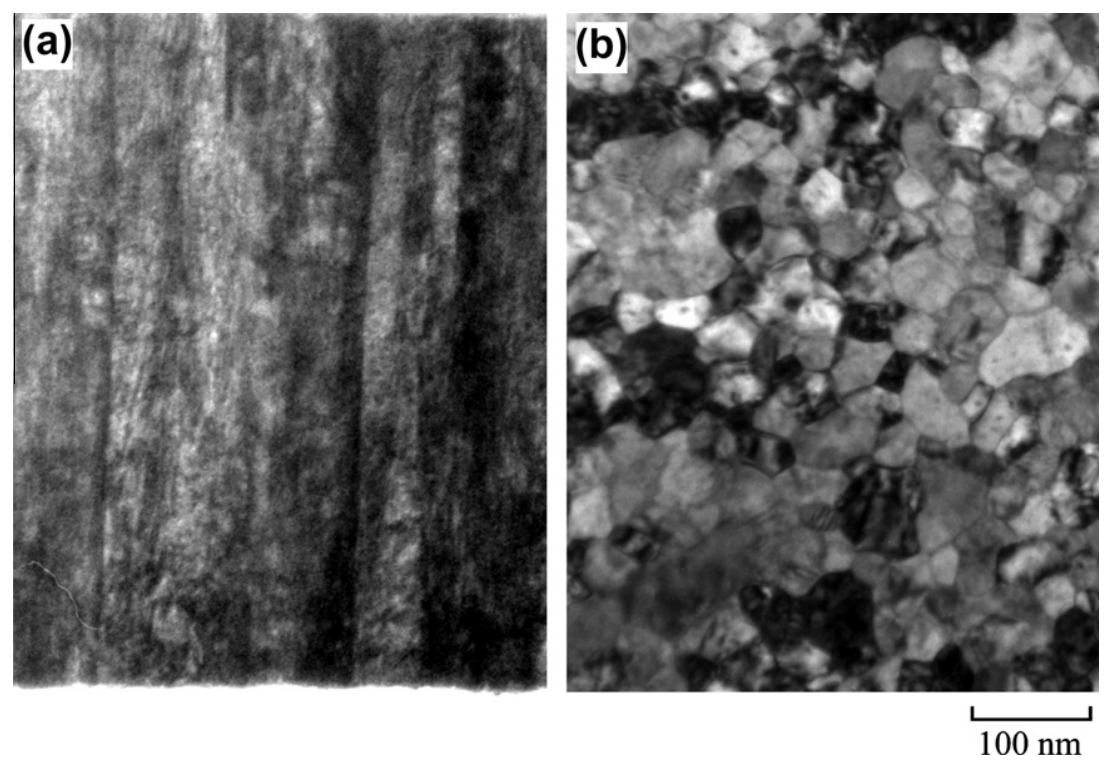

Fig. 1. (a) Cross-sectional TEM micrograph of the full height of the platinum and its $25 \pm 10 \mathrm{~nm}$ diameter, through-thickness columnar grains. (b) Planview TEM micrograph of the Pt grains confirming their size and uniform distribution.

specimens (ovaloid central notches with $3 \mu \mathrm{m}$ radius, semicircular ends spanning $33 \%$ of the gauge widths $(200,150$ and $100 \mu \mathrm{m}$ ); Fig. 2) for fatigue crack growth testing. Prior to tension and fatigue testing, the silicon dies containing the specimens were adhered to the displacement stage and a $200 \mu \mathrm{m}$ diameter optical fiber or a blunted $20 \mu \mathrm{m}$ tip diameter tungsten needle was connected to the load cell via a collet grip adapter. The tungsten needle was then affixed the specimens with an ultraviolet light curable adhesive (Dymax OP-24-REV-B).

Tensile tests were conducted in laboratory air $\left(22 \pm 2{ }^{\circ} \mathrm{C}\right)$. Due to the optically smooth surface of the films, artificial markers were introduced to the surface of tensile specimens using a Magnaflux Developer (SKD-S2) to measure strain-induced displacements of the film. Digital image correlation software was used to track displacement of the markers with a strain resolution of $10^{-4}$. The displacement-controlled tensile tests were conducted at a displacement rate of $1 \mu \mathrm{m} \mathrm{s}^{-1}$. The elastic modulus was calculated from the slope of the stress-strain curve that was fitted by a least-squares linear regression fit $\left(R^{2}>0.97\right)$. The yield point (proportional limit) was noted as the point in the curve which caused the $R^{2}$ value to drop below 0.97 .

The indentation behavior of the Pt films was evaluated using nanoindentation of the film on the Si substrate. Indents were performed in force control using a Hysitron TriboIndenter (Hysitron, Inc., Minneapolis, MN) with an acoustic enclosure that has been previously shown to have
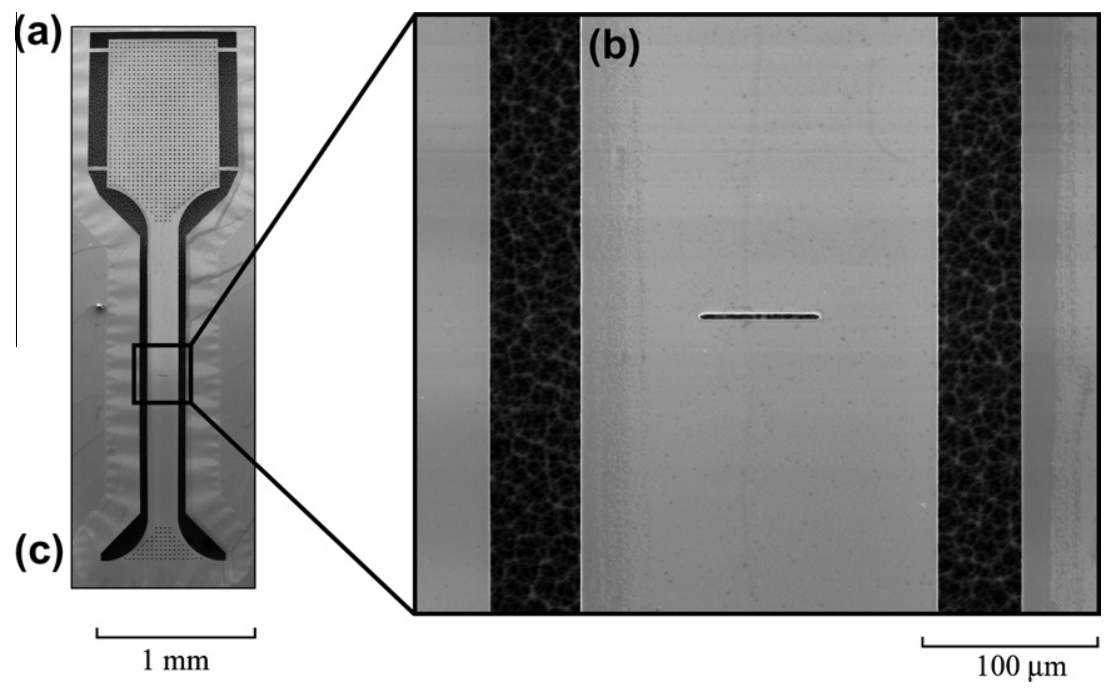

Fig. 2. A scanning electron micrograph of a fatigue crack growth characterization specimen showing (a) the free-standing grip section with tethers, (b) the free-standing gauge section with central ovaloid slot and (c) the "anchor" portion attached to the substrate. Tensile characterization specimens lacked the central slot, but were otherwise configured similarly. 
less than $0.1{ }^{\circ} \mathrm{C}$ variance over the course of a test [20]. A $500 \mathrm{~nm}$ conospherical diamond indenter tip was actuated into an area of the micromachined Pt film that still cohered well to the Si substrate. A trapezoidal waveform was used, with a $10 \mu \mathrm{N} \mathrm{s}^{-1}$ loading rate to a maximum force of $1500 \mu \mathrm{N}$, at which it was held for $10 \mathrm{~s}$ and then unloaded at $10 \mu \mathrm{N} \mathrm{s}^{-1}$. Both pre- and post-imaging of the indentation area were performed using the indenter tip in a scanning probe microscope configuration to confirm that they were free from debris and gross defects. A traditional Oliver-Pharr methodology was used to analyze the indentation data per ISO 14577 guidelines [21]. Both area function and compliance calibrations were performed on a reference Corning C1737F float glass and applied to the analysis of the Pt indents. Additionally, the plane strain elastic modulus and hardness values incorporated corrections for pile-up by measuring the average pile-up height around each indent in the scanning probe microscopy images. A correction was not made for substrate effects, due to slight viscoelastic behavior of the film; further information about this correction and the indentation technique can be found in Ref. [7].

The constant stress amplitude (maximum error \pm 10 $\mathrm{MPa}$ ) fatigue tests were conducted with a load ratio $\sigma_{\min } / \sigma_{\max }, R=0.1$, sinusoidal waveforms at $1 \mathrm{~Hz}$. The crack length during the test was measured from digital optical micrographs $(0.5 \mu \mathrm{m}$ resolution) that were captured during the experiment. The specimen compliance was determined from a least-squares linear regression of 100 equally spaced force and crosshead displacement data points in a given cycle. The linear elastic stress intensity factor, a measure of the driving force of crack advance, was calculated using established solutions by Tada et al. [22]. Fatigue crack growth rates were calculated by dividing the change in the optically measured crack length by the number of cycles that had elapsed. A three-point with $50 \%$ overlap modified secant method was applied to both stress intensity values and crack growth rates [23]. Due to the symmetric crack growth from both ends of the notch, the stress intensity factors and fatigue crack growth rates were averaged. The fracture toughness, $K_{\mathrm{q}}$, of the material was approximated as the maximum driving force in the cycle that preceded catastrophic failure of the specimen. After failure, fracture surfaces were imaged using a JEOL JSM-6700F field emission scanning electron microscope operating at acceleration voltages ranging from 5 to $15 \mathrm{kV}$. Fatigue tests on samples with arrays of notches with varying lengths (spaced far enough apart to be non-interacting [22]) were used to create intact specimens that could be prepared for TEM analysis without risk of introducing artifacts from the thinning process. In some cases, notches were created using a $\mathrm{Ga}^{+}$focused ion beam (FIB) system (FEI Quanta 200 3D). Because the damage induced by the FIB was confined to the region immediately adjacent to the notch $(\sim 100 \mathrm{~nm}$ or less) and the crack extension resolution was fivefold larger, no differences between the fatigue crack growth behavior of the lithographically patterned and FIB-machined specimens were observed.
Plan-view TEM specimens were made from fatiguecracked specimens via FIB (FEI Strata DB235 FIB). Areas of approximately $20 \mu \mathrm{m} \times 25 \mu \mathrm{m}$ were extracted with the FIB and placed on TEM shelf-grids using an in situ micromanipulator (Omniprobe ${ }^{\mathrm{TM}}$ ). A $5 \mu \mathrm{m}$ wide band around the region of interest of each specimen was thinned to electron transparency using the FIB after reorienting the grid to an upright position and depositing a protective layer of $\mathrm{Pt}$ on the sidewall surface of the film. Cross-section TEM samples of residual indents and interaction volumes were created using conventional FIB lift-out techniques [24]. TEM imaging of both sets of samples was conducted in a $300 \mathrm{kV}$ JEOL $3010\left(\mathrm{LaB}_{6}\right)$ and a $200 \mathrm{kV}$ Philips CM200FEG. More details on the sample preparation are found in Ref. [25].

\section{Results and discussion}

Four uniaxial tension tests were performed on platinum films (Fig. 3) from the first fabrication run. The films displayed a yield strength of $1.5 \pm 0.1 \mathrm{GPa}$ and an ultimate strength of $1.75 \pm 0.05 \mathrm{GPa}$, and had an elastic modulus of $158 \pm 5 \mathrm{GPa}$. The failure surfaces were inclined $\sim 40^{\circ}$ from the tensile loading axis. The high values of both the yield and ultimate strengths are consistent with the high strength associated with fcc metals with such a fine nanoscale microstructure. The elastic modulus is low compared to that of bulk microcrystalline platinum, but is consistent with the trends in fcc metal films found by other researchers [26]. The fracture surfaces of these films displayed a typical transgranular crack path associated with dislocationmediated plasticity and failure. The significant plasticity in the films, seen both in the stress-strain curve and from the fracture surfaces, is consistent with the ductility expected from fcc metals and confirms that the films are not "embrittled" by grain boundary contaminants or voids.

A series of 10 indents was made into the platinum films on the silicon substrate from the second fabrication run. Using the Oliver-Pharr analysis, the average plane strain

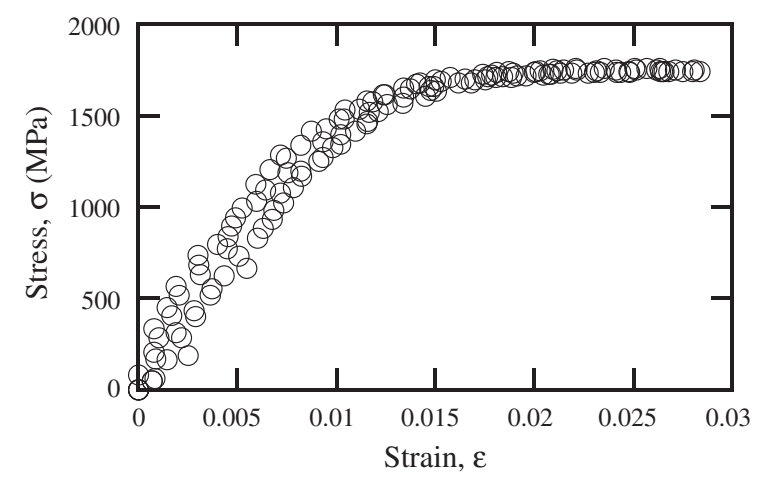

Fig. 3. A stress-strain graph compiling results from four uniaxial tension tests of constant gauge-width samples. The platinum films show a yield strength of $\sim 1.5 \mathrm{GPa}$ and an ultimate strength of $\sim 1.76 \mathrm{GPa}$, as well as a substantial amount of plastic deformation prior to failure, all consistent with ductile metallic films. All error is contained within the marker size. 
modulus of the blanket films on the silicon substrate was $221 \pm 2 \mathrm{GPa}$, which compares favorably with the 213 GPa predicted by the Vlassak and Nix anisotropic elasticity solution [27]. The average nanoindentation hardness of $7.4 \pm 0.1 \mathrm{GPa}$ was consistent with the tensile results reported above. The difference between these results and those reported in Ref. [7] is most likely due to spatial variations within the film itself. The regions tested were several millimeters apart, but their individual results were confirmed by repeat experiments (in separate sessions) within each region. Residual indents resulting from nanoindentation were studied by TEM to confirm the stability of the microstructure in response to compression loads. The TEM micrographs reveal no measurable grain coarsening or change to the dislocation density within the interaction volume (Fig. 4). The tension and indentation results suggest that the films have a stable microstructure even under high loads and are mechanically robust.

Four constant stress amplitude fatigue tests were performed on free-standing notched samples from the second fabrication run. During the fatigue crack growth tests, cracks grew symmetrically from the notches and exhibited straight (i.e. nominally mode I) crack paths, and no surface distortions associated with the development of the plastic zone were observed (Fig. 5). Final rupture of the specimens occurred on paths that were inclined $\sim 40^{\circ}$ from the tensile loading axis after an unknown amount of stable, ductile tearing. The symmetry of the crack extension from both

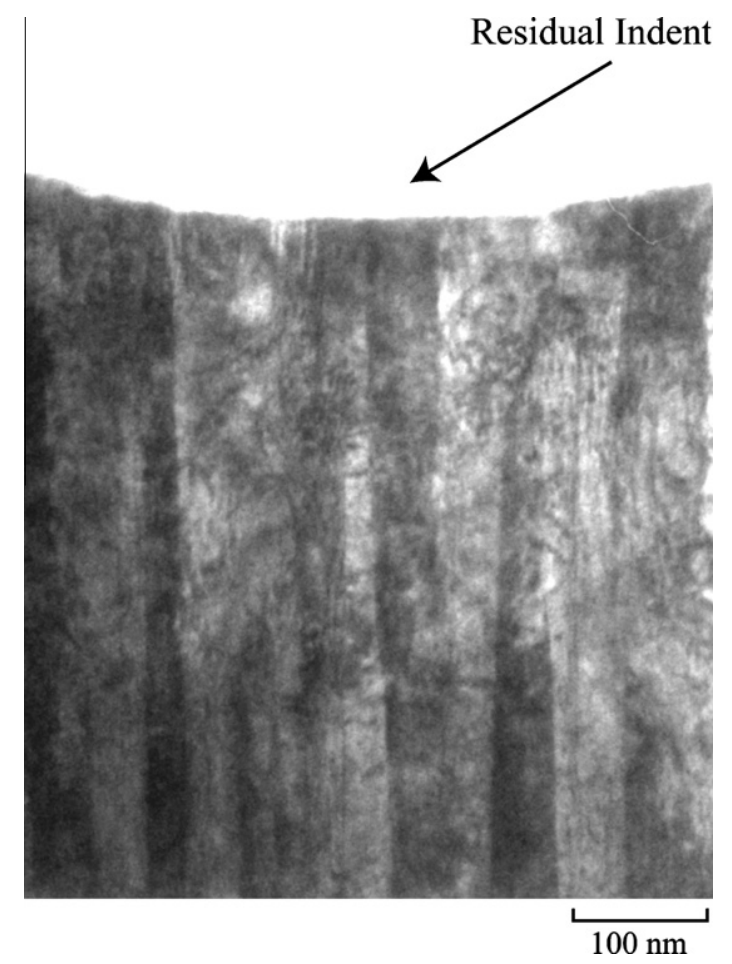

Fig. 4. Bright-field TEM image of a cross-section of a residual indent left over from a representative instrumented nanoindentation test of the platinum surface. Note that the microstructure is similar to that of the asreceived specimens shown in Fig. 2a, and that there is no measurable amount of grain coarsening within the interaction volume.
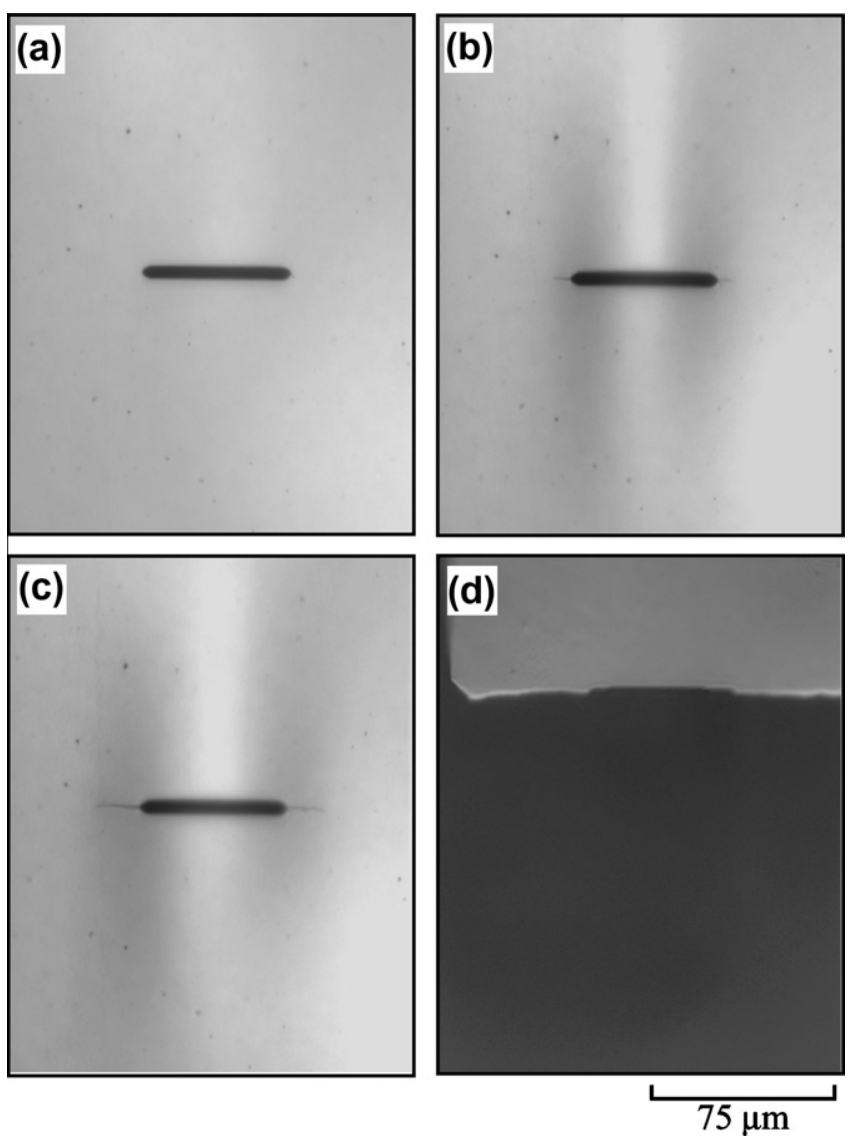

Fig. 5. Optical images acquired during fatigue testing of a nanocrystalline Pt film (test 3) showing (a) the initial ovaloid slot, (b) a crack at $50 \%$ of the critical crack size, (c) a crack at $75 \%$ of the critical crack size and (d) the sample after fracture.

ends allows for reasonable averaging of the two crack lengths. This symmetric growth is also a testament to the uniaxial conditions of the testing setup, as well as the overall uniform material properties of the nanocrystalline platinum.

The measured fatigue crack growth rates as a function of the applied stress intensity factor ranges are shown in (Fig. 6). An extremely limited range of fatigue crack growth was observed $(\sim 2.5 \mathrm{MPa} \sqrt{ } \mathrm{m})$, and a least-squares curve fit of the data to a power law relationship between the fatigue crack growth rate, $\mathrm{d} a / \mathrm{d} N$, and the applied stress intensity factor range, $\Delta K$, (i.e. $\mathrm{d} a / \mathrm{d} N=C(\Delta K)^{m}$ where $C$ and $m$ are fit parameters) provided a large power law exponent, $m$, of $\sim 10.5$. The fracture toughness, $K_{\mathrm{q}}$, ranged from 3.45 to $4.88 \mathrm{MPa} \sqrt{ } \mathrm{m}$. In contrast to bulk microcrystalline metals, the nanograined Pt films in this investigation exhibited fatigue crack growth rate trends that were reminiscent of extrinsically toughened structural ceramics and ordered intermetallics (i.e. $m>10$ ). Consistent with this observation, the fracture toughness of the nanograined $\mathrm{Pt}$ film was exceptionally low, $\sim 10$ times less than the micrograined form of the material [28].

The fatigue crack path in the near-threshold regime (i.e. growth rates below $10^{-9} \mathrm{~m} \mathrm{cycle}^{-1}$ ) and up to $\sim 2 \times 10^{-7} \mathrm{~m}$ 


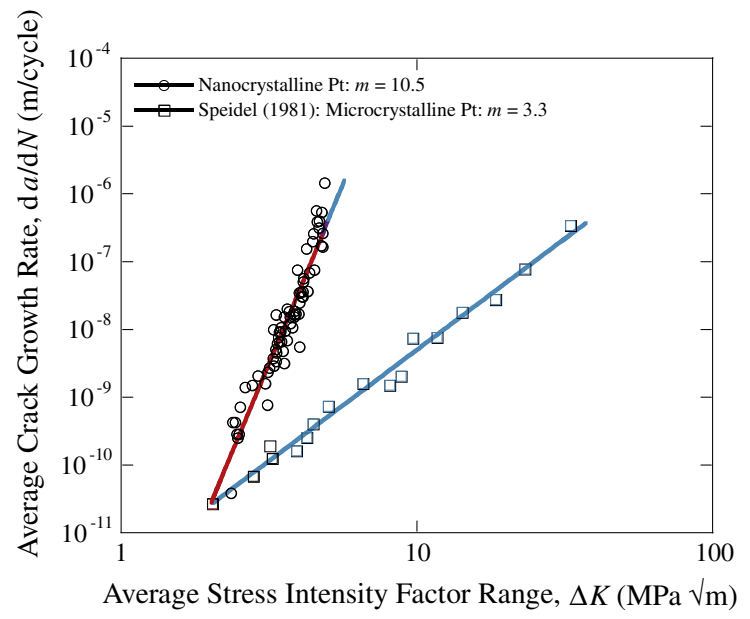

Fig. 6. Empirically measured fatigue crack growth behavior of nanograined Pt films (open circles) compared to previously published data for micrograined Pt by Speidel (open squares) [28]. The power law fit of the nanograined $\mathrm{Pt}$ (solid line) indicates a high power law exponent $(m=10.5)$ when compared to the microcrystalline Pt behavior $(m=3.3)$. All error is contained within the marker size.

cycle $^{-1}$ was intergranular (Fig. 7, left). Images from this region reveal visible grains and secondary cracking. As the cracks grew in length and accelerated to $\sim 3 \times 10^{-7} \mathrm{~m}$ cycle $^{-1}$, they gradually changed to a transgranular path (Fig. 7, center). During this transition, a fine ridge parallel to the crack propagation direction developed in the center of the failure surfaces. This relatively short section exhibited a mixture of the features of the neighboring inter- and transgranular regions. The transgranular mode dominated the crack path at growth rates larger than $4 \times 10^{-7} \mathrm{~m} \mathrm{cycle}^{-1}$ (Fig. 7, right).

The contribution of intrinsic and extrinsic mechanisms to the fatigue crack growth resistance of a material (i.e. mechanisms that operate ahead and in the wake of the crack tip, respectively) can be deduced from the shape of the cracked specimen compliance curves [29,30]. Devia- tions from linearity upon partial unloading usually indicate that the crack faces have come into contact and that the effective driving force for fatigue crack growth has been reduced. It is interesting to note that the data for coarsegrained, bulk Pt published by Speidel ([28]; Fig. 6) was presented in a "closure-corrected" form, and therefore represents the material's intrinsic resistance to fatigue crack growth. One cannot help but wonder if the higher fatigue crack growth rate exponent for the textured, nanograined $\mathrm{Pt}$ (Fig. 6) has intrinsic or extrinsic origins. If the grain size is fine or the film is thin enough, it could be argued that the cyclic plastic deformation mechanisms should be different and the power law exponent may change. Similarly, the secondary cracking observed in at low fatigue crack growth rates in the Pt films (Fig. 7a) could indicate that crack bridging and other shielding mechanisms are important. Crack closure is typically more dominant at low $\Delta K$ and lower load ratios due to the smaller crack opening displacements, so if present it should be easily observed under the testing conditions used in this study. Although significant microcracking was observed, the compliance curves collected during fatigue crack growth in the Pt films were linear for the range of fatigue crack growth rates that were measured [31]. Consequently, extrinsic mechanisms play a minimal role in fatigue crack growth in the Pt films. This observation is in contrast with findings by Suresh et al. [2], which alluded to the importance of intrinsic mechanisms in nanocrystalline materials, but no change in power law exponent was observed.

TEM analysis was performed on fatigue and fracture crack profiles so that the evolution in the grain morphology could be correlated with the features that were observed on the fracture surfaces. The TEM images from a crack whose growth rates were less than $2 \times 10^{-7} \mathrm{~m}_{\text {cycle }}{ }^{-1}$ (i.e. confined to the intergranular region) show clear evidence of increased grain size in the wake and ahead of the crack tip (Fig. 8) and a tortuous, intergranular path. The grains within $500 \mathrm{~nm}$ of the crack have undergone a nearly 10 -fold

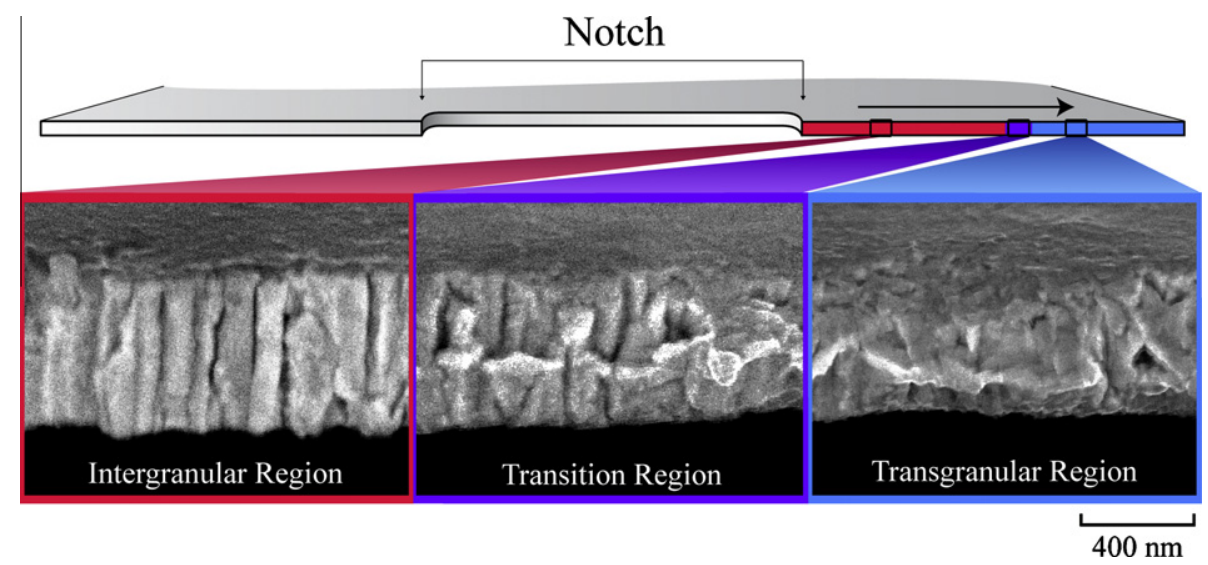

Fig. 7. Scanning electron micrographs of a typical Pt film fatigue failure surface in relation to the original sample. As the crack advanced from left to right, the crack propagated via an intergranular path (left). As the fatigue crack growth rate reached $\sim 2 \times 10^{-7} \mathrm{~m}$ cycle ${ }^{-1}$, the growth mode changed to a mixed inter- and transgranular morphology (center). Above $\sim 3 \times 10^{-7} \mathrm{~m}_{\text {cycle }}^{-1}$, the crack path was transgranular (right), with a central ridge that was associated with localized necking. 


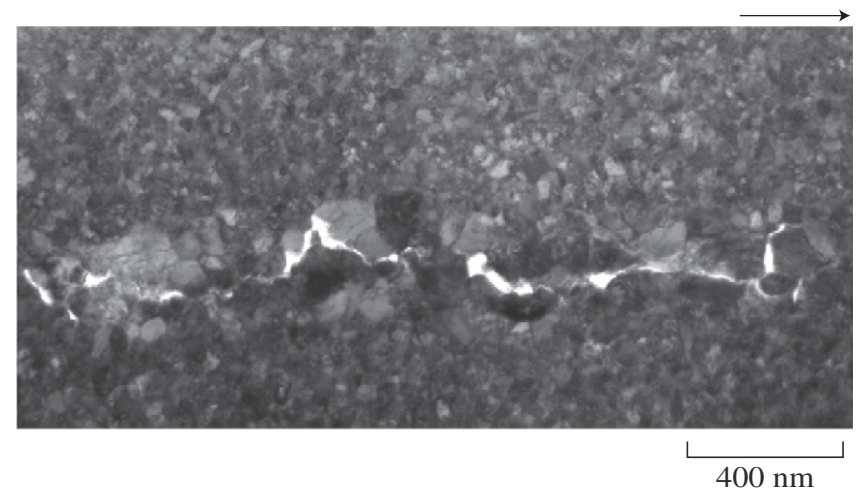

Fig. 8. Bright-field TEM image of fatigue crack path $(\Delta K=\sim 4.5 \mathrm{MPa}$ $\sqrt{ } \mathrm{m}$ ) showing effects of stress-assisted grain growth along the intergranular crack path region. Grains coarsened up to 10 -fold are found along the crack path. Coarsened grains are also visible ahead of the crack tip at the far right. Note that the apparent bridging of grains along the crack path is an artifact of the slight tilt of the specimen in the TEM. (The arrow denotes the crack growth direction.)

increase in size when compared to the surrounding material. Moreover, the dislocation density in the coarsened grains is similar to that in the unchanged grains. Selected area diffraction confirmed that the coarsened grains maintained their $\left\langle\begin{array}{llll}1 & 1 & 1\end{array}\right\rangle$ orientation after the fatigue crack passed. TEM crack profiles from growth rate regimes where a central ridge is present on the fracture surface (i.e. crack growth rates exceeding $3 \times 10^{-7} \mathrm{~m} \mathrm{cycle}^{-1}$ ) show no evidence of grain coarsening. Moreover, several grains appear to have been bisected by the crack path, confirming the transgranular nature of the cracking process at these crack growth rates. Collectively, these observations imply that grain growth is primarily a fatigue-driven process that is intrinsic in origin.

Although the details of the fatigue mechanisms are not completely apparent, the mechanical testing and electron microscopy data presented herein allow us to define their salient features. First, and arguably most important, fatigue crack growth in the platinum films is dominated by cycle-dependent plastic deformation that is mediated by dislocation motion. While the dislocation activity cannot be observed directly without thinning the specimens, features of the fracture surface make it clear that dislocation motion is important. The $\sim 40^{\circ}$ inclined fracture surfaces that develop from tensile overload, ductile tearing and unstable crack growth exhibit a distinctively transgranular appearance. Moreover, the grain structure maintains its nanoscale character, and intergranular voiding that would result from severe grain rotation was not observed. While it was not possible to identify significant changes in dislocation density (not unusual for nanograined metals) or to observe them directly during the degradation process, the inclination of the fracture surface and its morphology are traditional hallmarks of dislocation-based plasticity.

A characteristic feature of textured fcc metal fatigue is the evolution of the fatigue crack path from inter- to transgranular. The fatigue failure surfaces at low fatigue crack paths are clearly intergranular. As the fatigue crack growth rate increases, the mode changes to transgranular and a central "ridge" develops. While this typical feature has not been explicitly noted by other authors (e.g. see Fig. 10 of Ref. [32]), we have also observed it in $2 \mu \mathrm{m}$ thick, micrograined, textured Au films (R.A. Meirom, unpublished results). Given the well-established relationship between dislocation slip and the fatigue crack path, it is likely that the evolution of the crack path is a natural byproduct of the constrained dislocation slip in the textured film. Initially, dislocation slip is restricted to the best oriented $\left\langle\begin{array}{llll}1 & 1 & 0\end{array}\right\rangle$ [7] system. As the crack tip stress field becomes more intense, additional transverse planes allow for through-thickness slip of dislocations. This evolution is similar to the plane strain to plane stress transitions that occur in single crystals [33]. While this trend appears in both nano- and micrograined textured films, there is an important grain-coarsening phenomenon that is enabled by cyclic plastic deformation.

Plastic deformation in metals usually leads to the formation of dislocation networks [34]. Depending on the magnitude of the strain and the loading type (monotonic or cyclic), the size and arrangements change. Alternating areas of high and low dislocation density form, and the characteristic patterns of low dislocation density are initially isolated ("cells") and become interconnected ("labyrinth") until cracking and decohesion occur at "ladderlike" persistent slip bands. In the case of ultrafine and nanograined films, these networks are often not found because they cannot form within a single grain. It is important to note that the absence of these networks does not necessarily mean that dislocation motion does not occur and that (usually) elevated temperature mechanisms such as grain boundary sliding must be active. Instead, the grain boundaries must act as sources and sinks for the dislocations. In the special case of textured fcc films, the angles that arise between adjacent grains are usually low angles. In fact, our TEM evaluations showed that the angle can be so small that it is difficult in many cases to distinguish between grains. In this situation, we postulate that the motion of dislocations allows for the progressive coarsening of the grains. Recall that TEM analysis reveals that a large portion of the crack path is intergranular and that the grain size adjacent to the crack has increased $\sim 10$-fold. Moreover, the coarsening is clearly visible ahead of the crack tip and the intergranular fracture surface has through-thickness, linear features that are reminiscent of the original columnar grains. This suggests that clusters of grains consolidate by the annihilation of a portion of the grain boundaries instead of a process which allows larger grains to grow at the expense of smaller ones. However, as the crack accelerates, the grain size remains essentially unchanged, even during unstable crack growth. These additional observations provide crucial insight into how fatigue damage occurs.

The combination of fatigue-driven grain coarsening and crack advance can be accommodated by three possible sequences of events. One option would be for coarsening 
to happen spontaneously after passage of the crack in between the grains. Such a process would be expected to be more extensive when plastic deformation is more severe - such as at high crack growth rates and during tensile overload. Given that the coarsening is observed ahead of the crack tip in the TEM crack profiles and only at low fatigue crack growth rates, it is unlikely that the coarsening and crack growth can be decoupled. This essentially rules out that the underlying mechanisms that are a cyclic analog to self-annealing or recrystallization and grain growth at a newly formed free surface. The second option is that the grain coarsening must occur before the crack advances along the grain boundaries. Given the transition to a transgranular path at higher growth rates (i.e. cracking with a notable absence of grain coarsening), this sequence of events is also improbable. Instead, the third sequence is most likely - cyclic crack advance and grain coarsening must occur simultaneously, and are likely competing processes. The simultaneous coarsening and crack advance competition allows us to reconcile the experimental data in this study as well as some well-established trends in the literature.

The most likely sequence of events is that cyclic/reverse slip of dislocations near the crack tip causes some grain boundaries (low angle) to be annihilated prior to crack advance during relatively low stresses. The result is effective grain growth that requires cyclic deformation. Moreover, this grain-coarsening mechanism will maintain the outer boundary that is made up of a series of columnar grains; this periodicity and distinctive intergranular crack path would appear (consistent with the scanning electron micrographs). The crack will then grow along the weakened grain boundary, probably consistent with criteria such as those developed by Liu et al. [35]. The transition from intergranular to transgranular growth modes is likely due to competition with a second mechanism; at higher stresses and consequent loss of slip constraints, inclined slip planes can be activated, allowing typical transgranular plasticity to occur. This loss of crack tip constraint (i.e. a plane strain to plane stress transition) would give rise to both a transgranular fracture mode and a central ridge on the fracture surfaces. Moreover, it would also give rise to a transitional region between the two regions in which both mechanisms are operating. Our proposed set of competing mechanisms would explain the experimental observation of both the fracture surface and the evolution in microstructure, but does not adequately describe the high power law exponent and shortened fatigue crack growth range. These two results are most likely direct results of the thickness of the film, which would explain why other investigations of thicker nanocrystalline fcc metallic systems have not produced a similar response.

\section{Conclusions}

The fatigue behavior of pure, oriented nanocrystalline platinum thin films was evaluated in laboratory air. Nano- indentation and tension tests (yield and ultimate tensile stresses of $1.5 \pm 0.1$ and $1.75 \pm 0.05 \mathrm{GPa}$ respectively, and a hardness of $7.4 \pm 0.1 \mathrm{GPa}$ ) showed that the grain structure does not coarsen during tensile or indentation loading. Constant stress amplitude fatigue tests showed an extremely limited range of fatigue crack growth and a large power law exponent, $m$, of $\sim 10.5$. Field emission scanning electron microscopy and TEM analyses revealed that cyclic cracks advance via competition between dislocation-mediated grain coarsening (with intergranular cracking) and transgranular crack growth modes. However, the linear unloading compliance curves that were observed in the near-threshold regime suggest that the underlying mechanisms are intrinsic in origin.

\section{Acknowledgements}

Support for RAM and CLM was through "CAREER: Education and Research in Nanomaterial DegradationThe Road to Molecular Fatigue Studies". NSF CAREER Award (NSF DMR-0449684) and US Army Research Office (ARO W911NF-05-1-00640, Program manager Dr. Bruce LaMattina). This work was also supported by the Pennsylvania State University Materials Research Institute NanoFabrication Network and the National Science Foundation Cooperative Agreement No. 0335765 under Contract CMS-0528234, National Nanotechnology Infrastructure Network, with Cornell University. Support for D.H.A. and R.O.R. was from the Director, Office of Science, Office of Basic Energy Sciences, Division of Materials Sciences and Engineering, of the US Department of Energy under Contract No. DE-AC02-05CH11231. The authors would like to thank the staff, and are grateful for the use of the facilities, of the National Center for Electron Microscopy, Lawrence Berkeley National Laboratory, which is supported by the US Department of Energy under the same contract number. The authors would like to thank Joel Martin, Brian Power, Prashant Ranade and Richard Piekarz for their assistance in fabrication of the $\mathrm{Pt}$ specimens.

\section{References}

[1] Witney AB, Sanders PG, Weertman JR, Eastman JA. Scripta Metall Mater 1995;33:2025.

[2] Suresh S, Hanlon T, Tabachnikova ED. Int J Fatigue 2005;27:1147.

[3] Hoppel HW, Zhou ZM, Mughrabi H, Valiev RZ. Philos Mag A 2002;82:1781.

[4] Lukas P, Kunz L, Svoboda M. Mater Sci Eng A - Struct 2005;391:337.

[5] Padilla II HA, Boyce BL. Exp Mech 2010;50:5.

[6] Zhang K, Weertman JR, Eastman JA. Appl Phys Lett 2005;87.

[7] Cavaliere P, Suresh S. Mater Sci Forum 2007;1299.

[8] Suresh S, Hanlon T, Chokshi AH, Manoharan M. Int J Fatigue 2005;27:1159.

[9] Moser B, Hanlon T, Kumar KS, Suresh S. Scripta Mater 2006;54:1151.

[10] Romasco AL, Friedman LH, Fang L, Meirom RA, Clark TE, Polcawich RG, et al. Thin Solid Films 2010;518:3866. 
[11] Yamakov V, Saether E, Phillips DR, Glaessgen EH. J Mater Sci 2007;42:1466.

[12] Warner DH, Curtin WA, Qu S. Nat Mater 2007;6:876.

[13] Noronha SJ, Farkas D. Phys Rev B 2002;66:132103.

[14] Cao A, Wei Y. Phys Rev B 2007;76:24113.

[15] Farkas D, Curtin WA. Mater Sci Eng A - Struct 2005;412:316.

[16] Williams DB, Carter CB. Transmission electron microscopy. New York: Springer; 2009.

[17] MinCryst. $<$ http://database.iem.ac.ru/mincryst/> 2007.

[18] Wilson RG, Stevie FA, Magee CW. Secondary ion mass spectroscopy. New York: John Wiley \& Sons; 1989.

[19] Goodhew PJ, Humphreys J, Beanland R. Electron microscopy and analysis. New York: Taylor \& Francis; 2000.

[20] Romasco AL, Friedman LH, Fang L, Meirom RA, Clark TC, Polcawich R, et al. J Test Evalu 2010;38.

[21] ISO Standard 14577-4. Metallic materials - instrumented indentation test for hardness and material parameters. Geneva: ISO; 2007.

[22] Tada H, Paris PC, Irwin GR. The stress analysis of cracks handbook. New York: ASME Press; 2000.
[23] ASTM. E 647. In: Annual book of ASTM standards, 03.01. West Conshocken, PA: ASTM; 2005.

[24] Lucille A, Giannuzzi FAS. Introduction to focused ion beams: instrumentation, theory, techniques and practice. New York: Springer; 2004.

[25] Alsem DH, Dugger MT, Stach EA, Ritchie RO. J Microelectromech Syst 2008;17:1144.

[26] Sanders PG, Eastman JA, Weertman JR. Acta Mater 1997;45:4019.

[27] Vlassak JJ, Nix WD. Philos Mag A 1993;67:1045.

[28] Speidel MO. Platinum Met Rev 1981;25:24.

[29] Ritchie RO. Mater Sci Eng A - Struct 1988;A103:15.

[30] Ritchie RO. Int J Fract 1999;100:55.

[31] Meirom RA, Clark T, Polcawich R, Pulskamp J, Dubey M, Muhlstein CL. Phys Rev Lett 2008;101:085503.

[32] Park J-H, Myung MS, Kim Y-J. Sens Actuat A - Phys 2008;147:561.

[33] Rice JR, Hawk DE, Asaro RJ. Int J Fract 1990;42:301.

[34] Suresh S. Fatigue of materials. Cambridge: Cambridge University Press; 1998.

[35] Liu W, Bayerlein M, Mughrabi H, Day A, Quested PN. Acta Metall Mater 1992;40:1763. 